\title{
Immunohistochemical Characterization of Sudden Death While Bathing: Evaluating the Expression of SP-A, HSP70 and c-Fos Following Drowning and Thermal Stress
}

\author{
Makoto Sakurada ${ }^{1,2 *}$, Migiwa Asano ${ }^{1,3}$, Azumi Kuse $^{1}$, Mai Morichika1, Kanako Nakagawa ${ }^{1}$ and Yasuhiro Ueno \\ ${ }^{1}$ Division of Legal Medicine, Kobe University Graduate School of Medicine, 7-5-1 Kusunoki-cho, Chuo-ku, Kobe, Japan \\ ${ }^{2}$ Forensic Science Laboratory, Hyogo Prefectural Police Headquarters, 5-4-1 Shimoyamate-douri, Chuo-ku, Kobe, Japan \\ ${ }^{3}$ Division of Legal Medicine, Ehime University Graduate School of Medicine, Shitsukawa, Toon, Ehime, Japan
}

\begin{abstract}
Sudden death while bathing is a major issue in elderly Japanese individuals. Despite its growing incidence, the exact processes underlying sudden death while bathing remain unknown. This study was designed to establish reliable diagnostic markers for drowning while bathing, as well as to assess the pathological conditions associated with sudden death while bathing, by analyzing the immunohistochemical intensity and localization of surfactan protein-A (SP-A), heat shock protein 70 (HSP70) and c-Fos protein in the lungs and central nervous system, including the cerebral cortex and hippocampus. We found that a distinct pattern of immunohistochemical expression of SP-A HSP70 and c-Fos in the lung can be utilized to diagnose drowning. In most of these individuals, c-Fos protein was absent from the central nervous system, providing insight into patterns of ischemia in the central nervous system or a loss in consciousness while bathing. We also found that rapid hypothermia or a cold stimulus increased c-Fos expression in the hippocampus (CA4). Furthermore, our results suggest that HSP70 expression in the hippocampus (CA4) can be used to estimate the length of time between the initial occurrence of stress and death.
\end{abstract}

Keywords: Sudden death; Bathing; Immunohistochemistry; Environmental effect; Hypothermia; SP-A; c-Fos; HSP70

\section{Introduction}

The number of sudden deaths while bathing is increasing annually in Japan and now exceeds the number of deaths attributed to traffic accidents, making this an important social issue [1-3]. There is also a growing trend of surviving family members pursuing civil litigation to seek compensation from insurance companies. In such trials, a forensic pathologist must determine whether death was caused by natural pathological conditions preceding the drowning, or was an accidental drowning. This determination substantially influences the court's decision [3-5], and therefore requires absolute precision with a very narrow margin of error. Unfortunately, the circumstances of most of these deaths are unclear because they occur in closed spaces with little likelihood of eyewitness testimony. Thus, the cause of death must be determined from autopsy results [6-8]. While some of these deaths can be attributed to either disease or drowning, others are more challenging, with virtually no apparent macroscopic observations consistent with heart disease, cerebral vascular disease, or evidence of drowning [6].

We attempted to identify evidence indicative of drowning, as well as to characterize the pathophysiological features of sudden death while bathing at the microscopic level. We obtained organ samples from autopsies for patients who had died suddenly while bathing, had drowned, or had suffered from heart disease. Using

\begin{tabular}{|c|c|c|c|c|c|c|c|}
\hline \multirow{2}{*}{$\begin{array}{l}\text { Study } \\
\text { Cases }\end{array}$} & \multirow{2}{*}{$\begin{array}{l}\text { Sample } \\
\text { number }\end{array}$} & \multicolumn{2}{|c|}{ Sex } & \multicolumn{2}{c|}{ Age (years) } & \multicolumn{2}{c|}{$\begin{array}{c}\text { Postmortem } \\
\text { duration (hours) }\end{array}$} \\
\cline { 3 - 8 } & & Male & Female & Average & SD & Average & SD \\
\hline Group 1 & 13 & 9 & 4 & 78.1 & 9.6 & 16.9 & 4.5 \\
\hline Group 2 & 7 & 3 & 4 & 77.3 & 7.5 & 17.4 & 2.9 \\
\hline Group 3 & 11 & 5 & 6 & 60.5 & 17.4 & 17.6 & 4.7 \\
\hline Group 4 & 10 & 8 & 2 & 70.0 & 16.2 & 17.8 & 5.7 \\
\hline
\end{tabular}

Table 1: Summary of Samples (sample number, sex, age, postmortem duration). immunohistochemical analysis we compared the expression levels of certain proteins associated with various stress responses related to bathing, such as drowning, thermal stress, and ischemia.

\section{Materials and Methods}

\section{Tissue samples}

Tissue samples were obtained from forensic autopsies performed on 41 patients at the authors' respective institutions. The samples were divided into 4 groups (Table 1): patients who died suddenly while bathing with macroscopic findings consistent with drowning (Group $1 ; n=13)$; patients who died suddenly while bathing with no apparent macroscopic observations consistent with drowning (Group 2; $\mathrm{n}=7$ ); patients who drowned outdoors, such as in an ocean, lake, or pond (Group 3; $\mathrm{n}=11$ ); and patients who experienced acute death caused by ischemic heart disease (Group 4; $\mathrm{n}=10$ ). From autopsy results, the cause of death for Group 1 was determined to be drowning, whereas in Group 2 death was attributed to heart disease. Groups 3 and 4 were used as controls for Groups 1 and 2. The postmortem intervals between death and autopsy in this study were all restricted to within an estimated 48 $\mathrm{h}$ to obtain accurate immunohistochemical data. These intervals were estimated from autopsy results and reliable police information.

*Corresponding author: Makoto Sakurada, Ph.D, Division of Legal Medicine Kobe University Graduate School of Medicine, 7-5-1 Kusunoki-cho, Chuo-ku Kobe-650-0017, Japan, Tel: +81-78-382-5582; Fax: +81-78-382-5599; E-mail: makorin0819@maia.eonet.ne.jp

Received October 01, 2014; Accepted October 31, 2014; Published November 04, 2014

Citation: Sakurada M, Asano M, Kuse A, Morichika M, Nakagawa K, et al (2014) Immunohistochemical Characterization of Sudden Death While Bathing: Evaluating the Expression of SP-A, HSP70 and c-Fos Following Drowning and Thermal Stress. J Forensic Res 5: 249. doi:10.4172/2157-7145.1000249

Copyright: (c) 2014 Sakurada M, et al. This is an open-access article distributed under the terms of the Creative Commons Attribution License, which permits unrestricted use, distribution, and reproduction in any medium, provided the original author and source are credited. 
Citation: Sakurada M, Asano M, Kuse A, Morichika M, Nakagawa K, et al. (2014) Immunohistochemical Characterization of Sudden Death While Bathing: Evaluating the Expression of SP-A, HSP70 and c-Fos Following Drowning and Thermal Stress. J Forensic Res 5: 249. doi:10.4172/2157-7145.1000249

Page 2 of 5

Tissues from the lungs, cerebral cortex, and hippocampus were removed and fixed immediately in $10 \%$ formalin for $24 \mathrm{~h}$. Samples were embedded in paraffin and sectioned at $4-\mu \mathrm{m}$ intervals immediately prior to staining.

\section{Immunohistochemistry}

SP-A immunohistochemistry: Tissue samples were assayed immunohistochemically to localize human SP-A, a protein increased in drowning and asphyxiation [9,10], using the EnVision system (Dako). The sections were deparaffinized in xylene, rehydrated, and incubated with $3 \%$ hydrogen peroxide solution for 10 min to block endogeneous peroxidases. After washing in phosphate buffered saline (PBS, pH 7.4), the sections were incubated with 1:400 diluted anti-SP-A antibody (Dako) at room temperature for $30 \mathrm{~min}$. After washing three times in PBS for 5 min each, the sections were incubated with antimouse IgG antibody for $30 \mathrm{~min}$, stained with 3-3'diaminobenzidine tetrahydrochloride (DAB, Dako) solution and counterstained with Mayer's hematoxylin. Immunostaining specificity was confirmed using control slides omitting the primary antibody.

HSP70 immunohistochemistry: Heat shock protein 70 (HSP70) is thought to be universally induced in almost all cells placed under various stress conditions, including those in the Central Nervous System (CNS) [11-15], lungs [16-18], and kidneys [19]. Immunohistochemical detection of HSP70 was performed as above, except for antigen retrieval. Samples were incubated overnight at $4{ }^{\circ} \mathrm{C}$ with anti-HSP70 antibody (Thermo Scientific), diluted 1:600.

c-Fos immunohistochemistry: c-Fos is one of the initial genes activated by various stresses, including ischemia [20], seizures [21] and lesions [22,23]. Immunohistochemical detection of c-Fos was performed as above, except that the sections were incubated with 1:800 anti-c-Fos antibodies (Affinity Bioreagents) at room temperature for 30 $\min$.

\section{Immunopositivity evaluation}

SP-A expression in the upper lobe of both lungs was evaluated as described [9]. Two patterns of SP-A expression were observed: membranous or linear staining of the interior alveolar surface and the interface of the intra-alveolar effusion (pattern 1); and staining of intra-alveolar aggregated granular deposits (pattern 2). The intensity of immunoreactivity was classified as negative $(0)$, weakly positive $(+1)$, positive $(+2)$, or strongly positive $(+3)$, with pattern 2 including $(+2)$ a few or $(+3)$ many massive aggregates. Expression was assessed in 10 predetermined fields in each lung at a mean magnification of $\times 100$.

HSP70 and c-Fos expression was measured in alveolar cells in 5 fields of the upper lobe of each lung at high magnification $(\times 400)$. The percentage of positive cells for HSP70 and c-Fos was classified as $<5 \%$ (0), $5 \%$ to $10 \%(+1), 10 \%$ to $30 \%(+2)$, and $>30 \%(+3)$.

SP-A, HSP70 and c-Fos expression scoring for each magnification field in the lung was classified as grade 0 , arithmetic mean 0 to 0.49 ; grade 1 , arithmetic mean 0.5 to 1.49 ; grade 2 , arithmetic mean 1.5 to 2.49; grade 3 , arithmetic mean $>2.5$.

HSP70 and c-Fos expression in the cerebral cortex and hippocampus (CA1 and CA4) was assessed as the percent of positive neuronal cells in 5 fields at high magnification $(\times 400)$. Positive immunoreactivity was defined as staining of the cytoplasm and/or nucleus of neuronal cells.

All sections were evaluated by two independent investigators to minimize interobserver variability. The four datasets were compared using ANOVA, followed by the Tukey or Games-Howell test. All statistical analyses were performed using SPSS Student Version 13.0J software, with $\mathrm{P} \leq 0.05$ considered statistically significant.

Sections were also stained with Hematoxylin-Eosin (HE) to assess any morphological changes in tissue samples.

\section{Results}

\section{Histopathological analysis}

HE staining consistently revealed edema, congestion and hemorrhage in the lungs, along with edema and hemorrhage in the cerebral cortex and hippocampus of most patients.

\section{Immunohistochemistry}

No statistically significant correlations were observed between the degree of expression of the target proteins and age, sex or postmortem interval. Statistically significant correlations identified among the four groups in this study are shown in Table 2.

Detailed results of lung immunoreactivity are shown in Table 3. Immunohistochemical staining for SP-A showed a strongly positive pattern 2 staining (score $>2$, Figure 1a) in $77 \%$ of Group 1 and $82 \%$ of Group 3 samples, although $57 \%$ of Group 2 samples were also showed strong immunopositivity. Strong staining of alveolar epithelial cells for HSP70 (scores of +2 and higher) was observed in 7 of 20 (35\%) samples from Groups 1 and 2 (Figure 1b), indicating that high expression of HSP70 was more common in cases of sudden death while bathing than in control patients (Table 3 ). Alveolar epithelial cells from all 4 groups were weakly positive for c-Fos (Figure 1c), although stronger reactions occurred more frequently in cases of sudden death while bathing than in controls (Table 3).

Immunohistochemical examination of neuronal cells showed that HSP70 was usually expressed in the neurons of layers IV and II in the cerebral cortex, and in neurons, glial cells and vascular endothelial cells of the hippocampus. The four groups showed similar intensity and

\begin{tabular}{|c|c|c|c|}
\hline $\begin{array}{c}\text { Targeted } \\
\text { protein }\end{array}$ & $\begin{array}{c}\text { Expression } \\
\text { tissue(state) }\end{array}$ & Study group & $\begin{array}{c}\text { Significance } \\
\text { probability }\end{array}$ \\
\hline SP-A & Alveolar (pattern 2) & Group 1-Group 4 & 0.005 \\
\hline & Hippocampus CA4 & Group 3-Group 4 & 0.001 \\
\hline HSP & Group 1-Group 3 & 0.028 \\
\hline C-Fos & Hippocampus CA1 & Group 1-Group 3 & $<0.001$ \\
\hline & & Group 2-Group 3 & $<0.001$ \\
\hline & Hippocampus CA4 & Group 1-Group 3 & $<0.001$ \\
\hline & & Group 1-Group 4 & 0.047 \\
\hline & & Group 2-Group 3 & $<0.001$ \\
\hline & & Group 2-Group 4 & 0.047 \\
\hline & Cerebral cortex & Group 1-Group 3 & $<0.001$ \\
\hline & & Group 2-Group 3 & $<0.001$ \\
\hline
\end{tabular}

Table 2: Results of statistical analysis by one-way ANOVA and multiple comparison.

\begin{tabular}{|c|c|c|c|c|c|c|c|c|c|c|c|c|c|c|c|c|}
\hline \multirow{3}{*}{ Study Cases } & \multicolumn{8}{|c|}{ SP-A Grade } & \multirow{2}{*}{\multicolumn{4}{|c|}{ HSP Grade }} & \multirow{2}{*}{\multicolumn{4}{|c|}{ c-Fos Grade }} \\
\hline & \multicolumn{4}{|c|}{ Pattern 1} & \multicolumn{4}{|c|}{ Pattern 2} & & & & & & & & \\
\hline & 0 & 1 & 2 & 3 & 0 & 1 & 2 & 3 & 0 & 1 & 2 & 3 & 0 & 1 & 2 & 3 \\
\hline Group $1(n=13)$ & 0 & 5 & 8 & 0 & 0 & 3 & 8 & 2 & 7 & 1 & 2 & 3 & 8 & 1 & 4 & 0 \\
\hline Group $2(n=7)$ & 1 & 3 & 3 & 0 & 0 & 3 & 4 & 0 & 2 & 3 & 1 & 1 & 4 & 1 & 2 & 0 \\
\hline Group $3(n=11)$ & 0 & 5 & 5 & 1 & 0 & 2 & 6 & 3 & 8 & 2 & 1 & 0 & 7 & 3 & 1 & 0 \\
\hline Group $4(n=10)$ & 0 & 3 & 7 & 0 & 1 & 8 & 1 & 0 & 7 & 3 & 0 & 0 & 8 & 2 & 0 & 0 \\
\hline
\end{tabular}

Table 3: Classification of intensity of targeted proteins expression in the lung by immunohistochemistry. 
Citation: Sakurada M, Asano M, Kuse A, Morichika M, Nakagawa K, et al. (2014) Immunohistochemical Characterization of Sudden Death While Bathing: Evaluating the Expression of SP-A, HSP70 and c-Fos Following Drowning and Thermal Stress. J Forensic Res 5: 249. doi:10.4172/2157-7145.1000249

Page 3 of 5

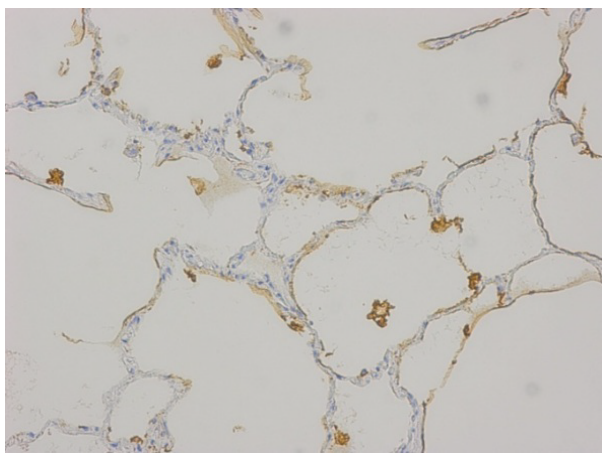

(1a)

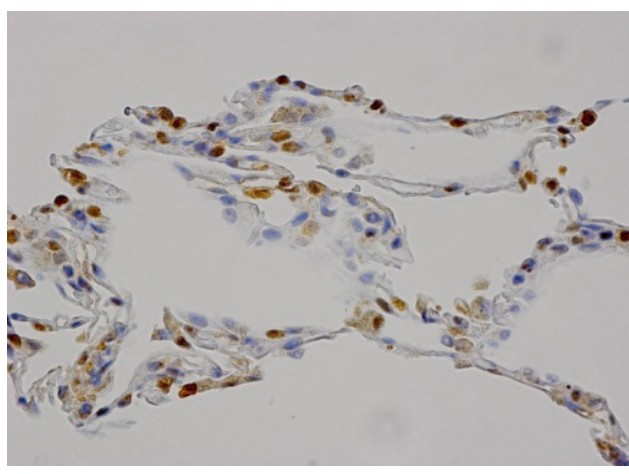

(1b)

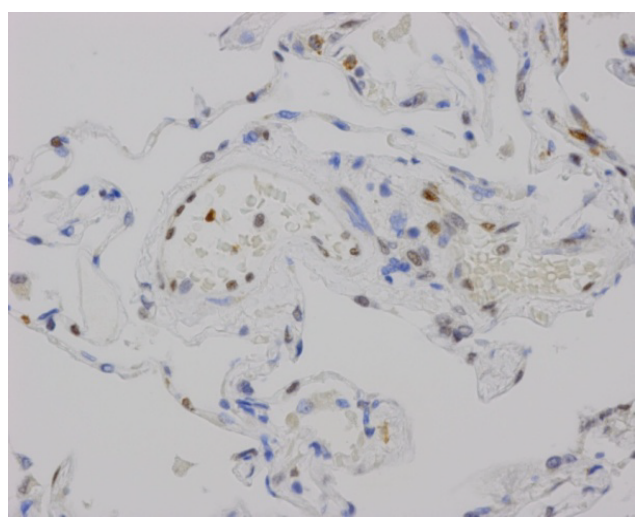

(1c)

Figure 1: (a-c) Representative examples of immunopositive reactions in the lung. All three samples were from Group 1, who experienced sudden death while bathing. (a) SP-A expression. Many massive aggregates of stained granules were observed in the intra-alveolar space (pattern 2: score $3, \times 200$ ). Positive reactions for (b) HSP70 (score $3, \times 400$ ) and (c) c-Fos (score 2, ×400) were observed in alveolar epithelial cells.

distribution of HSP70 in the cerebral cortex and in the hippocampus (CA1). Examination of the hippocampus (CA4) showed that, of the 20 patients in Groups 1 and 2, who died suddenly while bathing, 10 were strongly positive for HSP70 expression in neurons, whereas the other 10 were negative or only weakly positive (Figure $2 \mathrm{a}$ ).

Scattered neurons forming layers II-V in the cerebral cortex and in neurons, glial cells and vascular endothelial cells of the hippocampus were positive for c-Fos, although the only positive samples were from
Groups 3 and 4 (Figure 3). Moreover, staining patterns differed in these two groups, with most samples from Group 3 showing strong diffuse staining throughout the cytoplasm and sometimes the nucleus, whereas most samples from Group 4 showed staining mainly in the margins of cells. The intensity of distribution and staining pattern were similar in the cerebral cortex and hippocampus, although staining was greater in the hippocampus (CA4). A representative result of staining in the hippocampus (CA4) is shown in Figure $2 \mathrm{~b}$.

\section{Discussion}

\section{Diagnosis of drowningwhilebathingbyimmunohistochemical assays of several proteins}

Our results indicate that immunohistochemical expression of SP-A in lung is a highly useful marker in diagnosing drowning in the bathtub or outdoors. Although the mechanism underlying the formation of SP-A aggregates is unclear, massive aggregation of SP-A in the intra-alveolar space likely results from direct aspiration of water and respiratory distress [24].

Although the differences were not statistically significant, alveolar epithelial samples from Group 1 showed relatively stronger expression of c-Fos and HSP70 than samples from the other groups, with the difference greater for HSP70 than for c-Fos. Since HSP70 expression is elevated by various stresses, it is necessary to determine the probable trigger for elevated HSP70 expression in the lungs while bathing. Stresses associated with sudden death while bathing include drowning, cardiovascular responses, thermal effects and hydrostatic pressure caused by immersion of the entire body in a Japanese hot water bath, and aspiration of hot water into the lungs by drowning [2,25-28]. HSP70 expression may also be elevated by antemortem lung disease or injury. Macroscopic autopsy results did not detect any apparent lung disease in our patients, and increased HSP70 expression was not observed in Group 3. These findings suggest that thermal stress resulting from aspiration of hot water in the bathtub or increased core body temperature resulting from immersion in hot water for a certain period of time may have increased HSP70 expression in the lungs $[26,29,30]$. These findings suggest that both HSP70 and SP-A expression may be useful in diagnosing sudden death while bathing. However, some patients in our Group 1 showed only slight expression of HSP70, indicating the need for further investigations to determine whether the combination of elevated HSP70 and SP-A expression can be applied to practical autopsy results.

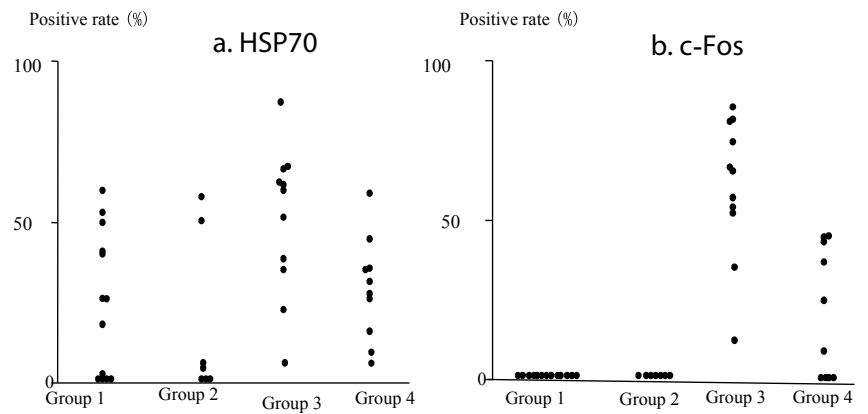

Figure 2: Percentage of neurons positive for (a) HSP70 and (b) c-Fos in the hippocampus (CA4) of the four Groups of patients. Group $1(n=13)$, sudden death while bathing with apparent macroscopic observations denoting drowning; Group $2(n=7)$, sudden death while bathing with no apparent macroscopic observations supporting evidence of drowning; Group $3(n=11)$, drowning outdoors (e.g. ocean, pond, etc.); Group $4(n=10)$, acute death from by ischemic heart disease. 
Citation: Sakurada M, Asano M, Kuse A, Morichika M, Nakagawa K, et al. (2014) Immunohistochemical Characterization of Sudden Death While Bathing: Evaluating the Expression of SP-A, HSP70 and c-Fos Following Drowning and Thermal Stress. J Forensic Res 5: 249. doi:10.4172/2157-7145.1000249

Page 4 of 5

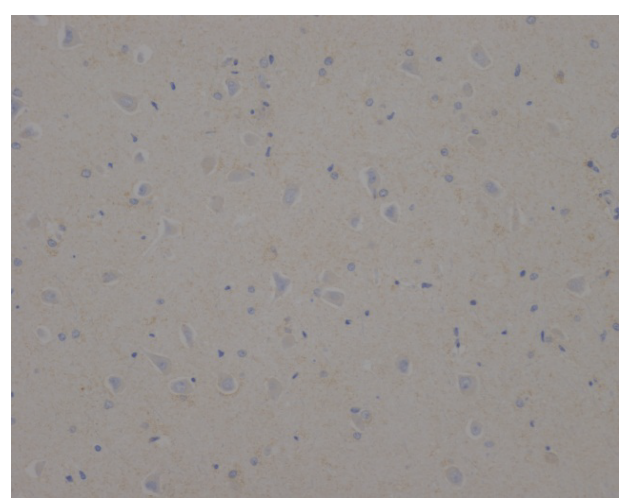

3(a)

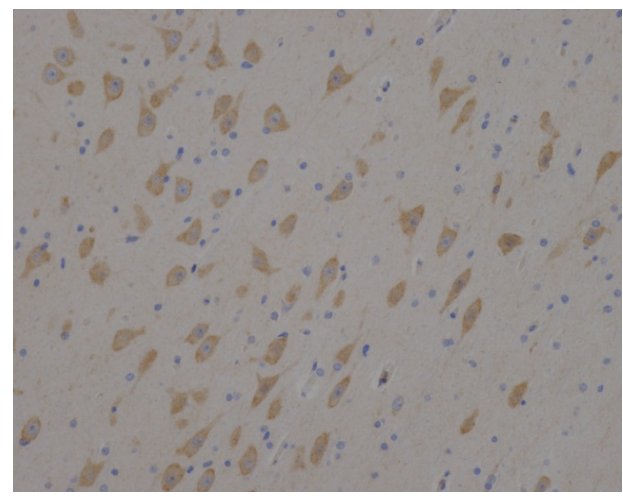

$3(\mathrm{~b})$

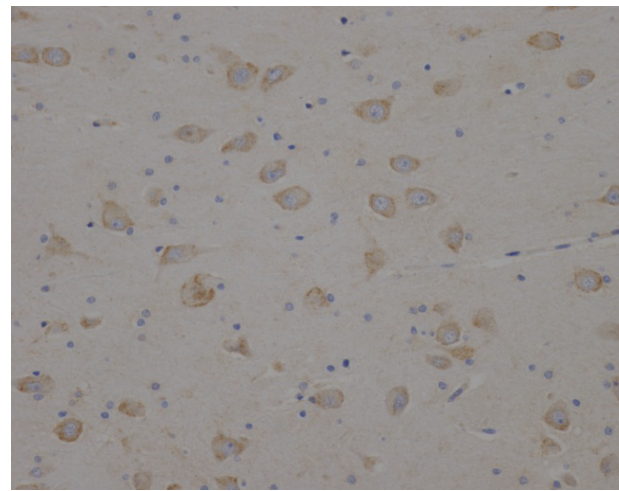

3(c)

Figure 3: (a-c) Representative examples of immunopositive reactions for c-Fos in the hippocampus (CA4) in samples from Groups 1 (a), 3 (b), and Group 4 (c) (×200). Hippocampal c-Fos expression was not observed in all samples from Groups 1 and 2. Most samples from Group 3 showed strong diffuse staining throughout the cytoplasm, with some also showing staining of the nucleus. Most samples from Group 4 showed staining in the margins of cells, with weaker intensity of staining.

Our Group 2 included patients who died suddenly while bathing, but included those with no apparent macroscopic evidence indicating that they had drowned; of this group; however, 2/7 showed similar immunohistochemical results as the patients in Group 1. Both of these patients may have aspirated water into the intra-alveolar space. Further investigations are needed to determine whether immunohistochemical assays for several proteins, including SP-A, HSP70, and c-Fos, can provide evidence of drowning, which results in accurate postmortem diagnoses in borderline cases in which sudden death occurred while bathing.

\section{Association between pathophysiological features of sudden death while bathing and HSP70 and c-Fos expression in central nervous tissue}

The levels of expression of HSP70 in the hippocampus (CA4) differed significantly between Groups 1 and 3 and between Groups 2 and 3. Some patients showed high $(>50 \%)$ and others extremely low $(<7 \%)$ positivity rates, with especially weak expression observed in 5 of the 7 (71\%) patients in Group 2. Autopsies of these 5 patients showed a myocardial infarction in 1 patient, whereas the other 4 had no apparent pathological abnormalities in the heart or brain. Elderly individuals are at risk of developing a potentially fatal arrhythmia while bathing [2], suggesting that the latter 4 patients may have suffered an arrhythmia while bathing. When an arrhythmic event becomes lethal within a short time, HSP70 expression may not be elevated due to the short time that proteins can be expressed. Therefore expression of HSP70 in the hippocampus (CA4) may be associated with the time between the occurrence of stress and ensuing death. HSP70 immunopositivity in the hypoglossal nerve and olivary nuclei has been reported unrelated to the interval between the initial occurrence of stress and death because immunoreactivity is influenced by factors such as the postmortem interval and environment [12]. While that report considers various postmortem environments [12], it may be difficult to extrapolate a meaningful relationship between immunoreactivity and the interval between the initial occurrence of stress and death.

Immunohistochemical expression of c-Fos in the hippocampus (CA4) differed significantly in Groups 3 and 4. Most samples from Group 3 showed strong diffuse staining throughout $>50 \%$ of neuronal cells, whereas samples from Group 4 showed staining of $<50 \%$ of neuronal cells, with the intensity of staining being weaker. Drowning has also been shown to induce c-Fos expression in the hypoglossal nucleus of the brain stem [13]. Interestingly, however, not all hippocampal samples from Groups 1 and 2 showed c-Fos expression, suggesting that drowning itself may not increase the hippocampal expression of c-Fos. Autopsy results showed that c-Fos positive patients in Group 4 had experienced a cardiac infarction several hours before death, suggesting that c-Fos expression may have been induced by ischemia of neuronal cells [31]. Alternatively, c-Fos expression was found to be induced by rapid hypothermia in rats under restraint water-immersion stress [32]. Similarly, all our Group 3 patients had drowned in the ocean, lakes and other bodies of water, with all being cold environments. Thus, rapid hypothermia or cold stimulus, either alone or together with other stresses such as asphyxia, may have elevated c-Fos expression in the hippocampus (CA4), possibly in concert with other stresses such as asphyxia [33]. Further investigations, including assays of individuals who experienced fatal hypothermia without drowning, are required to understand the mechanism regulating c-Fos expression in the hippocampus.

Almost none of the individuals who experienced sudden death while bathing showed c-Fos expression in the cerebral cortex and hippocampus, despite being under certain stresses. Japanese bathtubs are generally deeper, and the immersion temperature higher $\left(40-43^{\circ} \mathrm{C}\right)$, than in other countries. This combination may induce transient cerebral ischemia or a loss of consciousness while bathing [2,3]. Because c-Fos 
Citation: Sakurada M, Asano M, Kuse A, Morichika M, Nakagawa K, et al. (2014) Immunohistochemical Characterization of Sudden Death While Bathing: Evaluating the Expression of SP-A, HSP70 and c-Fos Following Drowning and Thermal Stress. J Forensic Res 5: 249. doi:10.4172/2157-7145.1000249

Page 5 of 5

has neuroprotective properties [34-36], the absence of c-Fos expression while bathing may be associated with neuronal activity during early phases of transient cerebral ischemia.

Our results indicate that immunohistochemical methods may be useful for assessing sudden death while bathing. Immunohistochemical assays of autopsy samples should consider certain factors, such as environment after death. Additional studies, involving a greater number of patients, are required to fully understand the pathophysiological features of sudden death while bathing.

\section{References}

1. Nagasawa Y, Komori S, Sato M, Tsuboi Y, Umetani K, et al. (2001) Effects of hot bath immersion on autonomic activity and hemodynamics: comparison of the elderly patient and the healthy young. Jpn Circ J 65: 587-592.

2. Chiba T, Yamauchi M, Nishida N, Kaneko T, Yoshizaki K, et al. (2005) Risk factors of sudden death in the Japanese hot bath in the senior population. Forensic Sci Int 149: 151-158.

3. Hatake K, Kudo R, Morimura Y, Kasuda S, Ishitani A (2005) Occurrence of sudden death in the bathroom investigated in Nara Prefecture and considerations of the cause of death in literature. J Nara Med Assoc 56: 235246 .

4. Hanrei Jiho (Law Cases Reports) (2009) No.2006: 146-159 (in Japanese).

5. Hanrei Jiho (Law Cases Reports) (2009) No.2036: 167-179 (in Japanese).

6. Yoshioka N, Nibe H, Enzan K, Shigeomi S (1998) Sudden death in the bathroom and its medico-legal issues. Res. Pract. Forens. Med 41: 353-359.

7. Funayama M, Yamaguchi Y, Tokudome S, Nakamura T, Matsu Y (1989) Death related to bath. Res. Pract. Forens. Med 32: 301-307.

8. Kurosaki K, Kurihara F, Hara S, Misawa S, Endo T et al. Questionable diagnoses on the cases of sudden death while bathing. Res. Pract. Forens. Med 45: 175-180.

9. Zhu BL, Ishida K, Fujita MQ, Maeda H (2000) Immunohistochemical investigation of a pulmonary surfactant in fatal mechanical asphyxia. Int J Legal Med 113: 268-271.

10. Pérez-Cárceles MD, Sibón A, Vizcaya MA, Osuna E, Gómez-Zapata M, et al. (2008) Histological findings and immunohistochemical surfactant protein A (SPA) expression in asphyxia: its application in the diagnosis of drowning. Histol Histopathol 23: 1061-1068.

11. Kitamura O (1994) Immunohistochemical investigation of hypoxic/ischemic brain damage in forensic autopsy cases. Int J Legal Med 107: 69-76.

12. Nogami M, Takatsu A, Endo N, Ishiyama I (1999) Immunohistochemical localization of heat shock protein 70 in the human medulla oblongata in forensic autopsies. Leg Med (Tokyo) 1: 198-203.

13. Gotohda T, Kubo S, Kitamura O, Tokunaga I, Eguchi A, et al. (2000) HSP70 and $\mathrm{c}-\mathrm{Fos}$ expression of brain stem hypoglossal nucleus in drowning. J Med Invest 47: 76-79.

14. Oechmichen M, Meissner C (2006) Cerebral hypoxia and ischemia: the forensic point of view: a review. J Forensic Sci 51: 880-887.

15. Zhan X, Kim C, Sharp FR (2008) Very brief focal ischemia simulating transient ischemic attacks (TIAs) can injure brain and induce Hsp70 protein. Brain Res 1234: 183-197.

16. Hagiwara S, Iwasaka H, Matsumoto S, Noguchi T, Yoshioka H (2007) Association between heat stress protein 70 induction and decreased pulmonary fibrosis in an animal model of acute lung injury. Lung 185: 287-293.

17. Marschall S, Rothschild MA, Bohnert M (2006) Expression of heat-shock protein 70 (Hsp70) in the respiratory tract and lungs of fire victims. Int $\mathrm{J}$ Legal Med 120: 355-359.

18. Inoue $H$, Nakagawa $Y$, Ikemura M, Usugi E, Nata M (2012) Molecular-biological analysis of acute lung injury (ALI) induced by heat exposure and/or intravenous administration of oleic acid. Leg Med (Tokyo) 14: 304-308.

19. Sakurada M, Asano M, Takahashi M, Kuse A, Morichika M, et al. (2013) Estimates of exposure to cold before death from immunohistochemical expression patterns of HSP70 in glomerular podocytes. Int J Legal Med 127: 783-790
20. Kumar K, Wu X, Evans AT (1996) Expression of c-fos and fos-B proteins following transient forebrain ischemia: effect of hypothermia. Brain Res Mol Brain Res 42: 337-343

21. Gass P, Herdegen T, Bravo R, Kiessling M (1992) Induction of immediate early gene encoded proteins in the rat hippocampus after bicuculline-induced seizures: differential expression of KROX-24, FOS and JUN proteins. Neuroscience 48: 315-324.

22. Dragunow M, Robertson HA (1988) Brain injury induces c-fos protein(s) in nerve and glial-like cells in adult mammalian brain. Brain Res 455: 295-299.

23. Haase M, Koslowski R, Lengnick A, Hahn R, Wenzel KW, et al. (1997) Cellular distribution of c-Jun and c-Fos in rat lung before and after bleomycin induced injury. Virchows Arch 431: 441-448.

24. Stemberga V, Stifter S, Cuculić D, Coklo M, Bosnar A (2009) Immunohistochemical surfactant protein-A expression: fatal drowning vs. postmortem immersion. Med Hypotheses 72: 413-415.

25. Kanda K, Tsuchiya J, Seto M, Ohnaka T, Tochihara Y (1995) Thermal conditions in the bathroom in winter and summer, and physiological responses of the elderly during bathing. Nihon Eiseigaku Zasshi 50: 595-603.

26. Chishaki A, Nagahiro C, Nagaie T, Shinohara J (2002) The physiological effects of hot bath immersion on human body-For the safe bathing, Memoirs Kyushu U. Sch. Health Sci $29: 9-19$ (in Japanese)

27. Yoshioka N, Chiba T, Yamauchi M, Monma T, Yoshizaki K (2003) Forensic consideration of death in the bathtub. Leg Med (Tokyo) 5 Suppl 1: S375-381.

28. Asakawa Y, Takahashi R, Endo F (2006) Cardiovascular responses during bathing in the elderly. Rigakuryoho Kagaku 21: 433-436.

29. Fargnoli J, Kunisada T, Fornace AJ Jr, Schneider EL, Holbrook NJ (1990) Decreased expression of heat shock protein $70 \mathrm{mRNA}$ and protein after heat treatment in cells of aged rats. Proc Natl Acad Sci U S A 87: 846-850.

30. Iguchi M, Littmann AE, Chang SH, Wester LA, Knipper JS, et al. (2012) Heat stress and cardiovascular, hormonal, and heat shock proteins in humans. J Ath Train 47: 184-190.

31. Rybnikova E, Glushchenko T, Tyulkova E, Baranova K, Samoilov M (2009) Mild hypobaric hypoxia preconditioning up-regulates expression of transcription factors c-Fos and NGFI-A in rat neocortex and hippocampus. Neurosci Res 65: 360-366.

32. Zhang YY, Zhu WX, Cao GH, Cui XY, Ai HB (2009) c-Fos expression in the supraoptic nucleus is the most intense during different durations of restraint water-immersion stress in the rat. J Physiol Sci 59: 367-375.

33. Nogami M, Takatsu A, Endo N, Ishiyama I (1999) Immunohistochemica localization of $\mathrm{c}$-fos in the nuclei of the medulla oblongata in relation to asphyxia. Int J Legal Med 112: 351-354.

34. Cho S, Park EM, Kim Y, Liu N, Gal J, et al. (2001) Early c-Fos induction after cerebral ischemia: a possible neuroprotective role. J Cereb Blood Flow Metab 21: $550-556$.

35. Yi JH, Park SW, Kapadia R, Vemuganti R (2007) Role of transcription factors in mediating post-ischemic cerebral inflammation and brain damage. Neurochem Int 50: 1014-1027.

36. Liu HG, Hua Z, Zhang Y, Wang YX, Meng C, et al. (2012) Effect of Sevoflurane postconditioning on gene expression in brain tissue of the middle cerebral artery occlusion rat model. Mol Biol Rep 39: 10505-10513. 